\title{
Thinking About Pedagogy: A Collection of Articles
}

\author{
Amy B. Shuffelton ${ }^{1}$ \\ Published online: 8 February 2022 \\ (c) The Author(s), under exclusive licence to Springer Nature B.V. 2022
}

It is likely no accident that over the course of 2021 authors offered Studies in Philosophy and Education a wealth of manuscripts about online education. Educators and students, from those who had been thinking about online education for years to those who had never taken a particular interest in the subject, were suddenly living it as never before. This issue of Studies presents three excellent new manuscripts that address philosophical questions made freshly relevant by the necessities of the Covid-19 pandemic.

The three papers about online education published together here were not written as a collection, but they speak to a common set of concerns. Three other papers in this issue, while not about online education per se, address aspects of pedagogy and classroom presence given a new twist by the pandemic. Each article stands by itself; read together, they showcase how philosophers of education are engaging with classroom instruction and its limitations in this unusual moment.

In “Grammars of On-Life Identities," Alberto Sánchez-Rojo, Ángel García del Dujo, José Manuel Muñoz-Rodrigues and Arsenio Dacosta question the dualistic distinction frequently made between "online" and "in person." "On-life" is the word they use to captures new ways in which communications technology mediate most human interactions. Their article explores the implications for education of "onlife" identity formation. For all the dramatic technological changes in recent years, the human body, of course, remains a factor, and in "The Presence of the Body in Digital Education," Carlos Willatt and Luis Manuel Flores take a phenomenological approach. Drawing on Merleau-Ponty, they also question the digital/corporeal dualism. In "Teaching Online in an Ethic of Hospitality," Rebeca Heringer revisits Claudia Ruitenberg's work on Derrida's ethic of hospitality, in the context of Covid-19 era classrooms.

Readers interested in classroom teaching in primary and secondary schools and in higher education will also enjoy both Federico Rovea's and Pål Opdal's articles on pedagogy. Rovea explores the ideas of Michel de Certeau, whose work has been extensively explored in other scholarly fields but less deeply in philosophy of education. Opdal questions the now-clichéd assumption that active learning is preferable to (presumed passive - but are they?) lectures.

In an era of increased pressure on educators and students to be always "on," and if not engaged in work intently engaging in various kinds of self-care for the sake of getting back to work, Rodrigo Brito, Stephen Joseph and Edward Sellman explore the

Amy B. Shuffelton

Ashuffe@luc.edu

1 Loyola University Chicago, Chicago, USA 
instrumentalization of mindfulness - and preferable interpretations of mindfulness-based interventions.

Read together, we hope, these articles will inspire ongoing philosophical conversation about pedagogy in the Covid-19 era and its aftermath.

Publisher's Note Springer Nature remains neutral with regard to jurisdictional claims in published maps and institutional affiliations. 